\title{
926.50430
}

RECEIVED

SEP 201996

OSTi

Laboratory Measurement Error

in External Dose Estimates and

Its Effects on Dose-Response

Analyses of Hanford Worker

Mortality Data

E. S. Gilbert

J. J. Fix

August 1996

Funded by Grant R01 0H3270

from the National Institute for Occupational

Safety and Health of the Centers for

Disease Control Prevention

Pacific Northwest National Laboratory

Operated for the U.S. Department of Energy

by Battelle 



\section{Laboratory Measurement Error in External Dose Estimates and Its Effects on Dose-Response Analyses of Hanford Worker Mortality Data}

E. S. Gilbert

J. J. Fix

August 1996

Funded by Grant R01 OH03270

from the National Institute for Occupational Safety and Health of the Centers for

Disease Control and Prevention

Pacific Northwest National Laboratory

Richland, Washington 99352 


\section{DISCLAIMER}

Portions of this document may be illegible in electronic image products. Images are produced from the best available original document. 


\section{Summary}

This report addresses laboratory measurement error in estimates of external doses obtained from personal dosimeters, and investigates the effects of these errors on linear dose-response analyses of data from epidemiologic studies of nuclear workers. These errors have the distinguishing feature that they are independent both across time (different measurements for the same worker) and across workers. An approach is developed for evaluating the effects of such errors provided that the nature and magnitude of the errors and their dependence on dose can be specified. In addition, materials relevant to determining the likely magnitude of errors for Hanford workers are reviewed. It is shown that even if very conservative assumptions about the magnitude of errors are made, it is very unlikely that laboratory errors have seriously distorted dose-response analyses of the Hanford worker data. Specifically, it has been demonstrated that the increase in an appropriate measure of the variance of the measured doses is unlikely be more than $1 \%$ of the variance of the true doses. The reason for the lack of distortion appears to be that larger doses, which are the most influential in dose-response analyses, are the sum of independent measurements from many dosimeters; thus, the relative error in such doses is small. Although the calculations made for this report were based on Hanford data, the overall conclusions are likely to be relevant for other epidemiologic studies of workers exposed-to external radiation. The report does not address all sources of error in external doses, and its conclusions are not applicable. to errors that are correlated across time and across workers. 

Contents

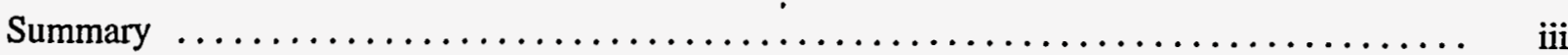

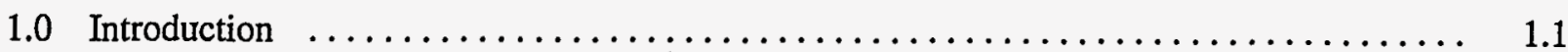

2.0 The Hanford Study Population $\ldots \ldots \ldots \ldots \ldots \ldots \ldots \ldots \ldots \ldots \ldots \ldots \ldots \ldots \ldots \ldots \ldots \ldots \ldots \ldots \ldots$

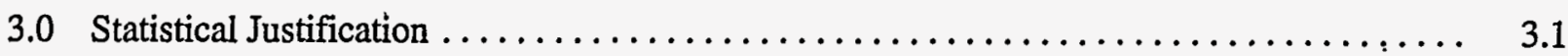

4.0 Approach for Evaluating the Statistic R, and Specification of Models for

Error Distributions . . . . . . . . . . . . . . . 4.1

5.0 Review of Materials Relevant to Quantifying Laboratory Measurement Errors in

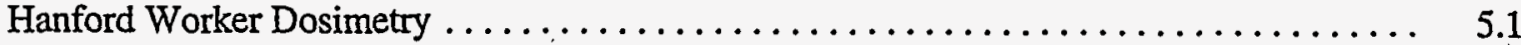

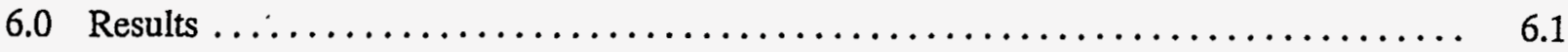

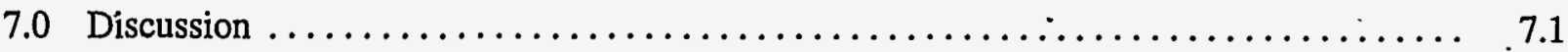

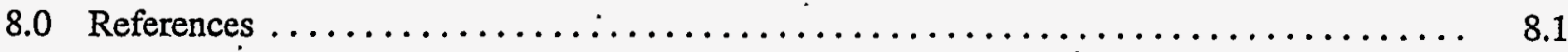

Appendix A - Derivation of the Asymptotic Relative Efficiency $\ldots \ldots \ldots \ldots \ldots \ldots \ldots \ldots \ldots$ A.1 


\section{Tables}

4.1 Variance of the Measured Doses Conditional on the True Doses for Individual Dosimeter Readings, Annual Doses, and Cumulative Doses for an Individual Worker

5.1 Summary of Information on Error Coefficients from Several Reports

6.1 Values of 1-R for Several Values of $\mathrm{K} 1, \mathrm{~K} 2, \mathrm{~K} 3$ Based on Cancer Mortality Data for Hanford Workers Excluding Workers with Confirmed Internal Intakes or with Potential for Neutron Exposure. Doses Lagged by 10 years . . . . . . . . . . . . . . . . . . .

6.2 Expressions for 1-R Based on Alternative Treatments of Hanford Mortality Data ........ 


\subsection{Introduction}

Recently, extensive efforts have been made to quantify biases and uncertainties in dose estimates for Hanford workers (Fix et al. 1995; Gilbert et al. 1996). These efforts focused on errors resulting from the inability of dosimeters to respond accurately to all energies and geometries. To the extent that workers remain in the same jobs in the same locations, such errors are likely to be correlated for different measurements for the same worker.

This report evaluates the effects on dose-response analyses of errors that are independent both across time (different measurements for the same worker) and across workers. ${ }^{(a)}$ The primary source of error meeting these criteria is laboratory measurement error, including particularly the intrinsic sampling variability in measurements from film badges and thermoluminescent dosimeters. The evaluation makes use of data from the Hanford worker cohort, but general conclusions are likely to be relevant for other epidemiologic studies of nuclear workers.

Dose-response analyses are strongly influenced by the small proportion of workers with relatively large estimated cumulative doses (in the range $50 \mathrm{mSv}$ and larger). Because estimates of these doses are the sum of many individual dosimeter readings, the relative errors in these estimates from sources that are independent for different measurements at different times are small. For this reason, it is conjectured that the effect of laboratory measurement errors (or any error that is independent across time) on dose-response analyses is likely to be small. The approach of this report is 1 ) to develop models for evaluating the effects of independent errors on dose-response analyses, 2) to review data that are relevant to quantifying errors for Hanford dosimetry systems, 3 ) and to quantify the effects of errors under various assumptions, particularly those judged applicable to Hanford.

Like our previous evaluation, the specific quantification of errors is limited to exposure from highenergy photons ( $2100 \mathrm{keV}$ ), the predominant exposure for most Hanford workers. For other types of exposure, such as that from neutrons or internal intakes, problems of bias are much more serious than those due to laboratory measurement error. As discussed by Gilbert and Fix (1995) and by Gilbert et al. (1996), it is probably better to exclude the small minority of workers with a substantial proportion of dose from these sources than to attempt to adjust for errors in their dose estimates.

This report does not address systematic bias that might result because of procedures for evaluating and interpreting exposures at or near background level, and does not address errors from sources that are not independent across workers and across time. These types of errors have been addressed in other reports (Gilbert and Fix 1995, Gilbert et al. 1996, Gilbèrt 1995a).

(a) This study was funded by Grant RO1 OH03270 from the National Institute for Occupational Safety and Health of the Centers for Disease Control and Prevention. 


\subsection{The Hanford Study Population}

A description of the Hanford worker study population and results of the most recent dose-response analyses of data from this study are given by Gilbert et al. (1993b). Dose estimates for Hanford . workers were obtained from personal dosimeters worn by workers and are subject to both systematic and random uncertainty. Several reports describe dosimetry practices at Hanford (Gilbert 1990; Wilson et al. 1990; Gilbert and Fix 1995) and detailed dose distributions for this population are given by Buschbom and Gilbert (1993).

Dosimetry practices at Hanford changed over time as technology evolved, and the personnel dosimeter programs in effect during various time periods have been described in detail by Wilson et al. (1990). The initial dosimeter used at Hanford starting in 1944 was a film badge dosimeter developed at the University of Chicago (Wilson 1987), and, at this time, dosimeters were exchanged weekly or biweekly. Major upgrades in the dosimeter program occurred in 1957-58 and in 1972. In 1957, an improved multi-element film badge dosimeter was introduced that allowed significant improvement in the measurement of low-energy photons, and in 1972 thermoluminescent dosimeters replaced film badges. In 1958, the frequency of dosimeter exchange was changed to monthly; in 1964, workers with limited potential for exposure were changed to quarterly monitoring; and in 1972, some workers were changed to yearly monitoring.

Computerized data on historical exposures includes annual doses, but does not include results of individual dosimeter readings or the number of dosimeters upon which the annual dose is based. This more detailed information is available only on microfilm or microfiche. 


\subsection{Statistical Justification}

Methods for analyzing data from nuclear worker studies, including the Hanford study, have been described in several places, including Gilbert (1989) and Gilbert et al. (1990). Most recent analyses have been based on the linear relative risk model, with the time variable $(t)$ taken to be age. That is, the relative risk is given by $1+B x(t)$, where the single covariate $x(t)$ is a measure of radiation exposure at age $t$, usually taken to be the cumulative dose up to a specified number of years prior to age $t$. For convenience, we use $x$ for $x(t)$ when no confusion is likely to result. The parameter $B$, which measures the proportional increase over baseline per unit of exposure, is referred to as the excess relative risk (ERR).

Let $i$ be index cases of the disease of interest $(i=1,2, \ldots \mathrm{m})$ with case $i$ occurring at age $t_{i}$; let $x_{i}$ be the dose of case $i$; and let $N_{i}$ denote the number of subjects in the risk set for case $i$, where the risk set consists of subjects at risk of disease at age $t_{i}$ who are similar to case $i$ with respect to specified stratification variables. In worker studies, these variables nearly always include calendar-year period and sex, and may also include measures of socio-economic status, length of employment, or initial year of employment. Finaily, let $M X_{i}$ be the mean of the doses in risk set $i$; that is, $M X_{i}=\sum_{j} x_{i j} / N_{i}$, where $j$ indexes subjects in risk set $i$. The efficient score statistic for testing the null hypothesis that $\beta=\beta_{0}$ is then given by

$$
\mathrm{UX}\left(\beta_{0}\right)=\Sigma \mathrm{i}_{\mathrm{i}}\left[\mathrm{x}_{\mathrm{i}} /\left(1+\beta_{0} \mathrm{x}_{\mathrm{i}}\right)-\cdot \mathrm{MX}_{\mathrm{i}} /\left(1+\beta_{0} \mathrm{MX} \mathrm{i}\right)\right]
$$

For testing the null hypothesis that $\beta=0$, this statistic becomes ·

$$
U X(0)=\Sigma_{i}\left(x_{i}-M X_{i}\right)
$$

The variance of. $\operatorname{UX}(\beta)$, conditional on the particular deaths that have occurred, can be estimated by the expected value of the derivative of the score statistic with respect to $\beta$. This is given by the expression

$$
\operatorname{VX}\left(\beta_{0}\right)=\sum_{i j} \sum_{N_{i}} \frac{1+\beta_{0} x_{i j}}{\left(1+\beta_{0} M X_{i}\right)} \times\left(\frac{x_{i j}^{2}}{\left(1+\beta_{0} x_{i j}\right)^{2}}-\frac{M X_{i}^{2}}{\left(1+\beta_{0} M X_{i}\right)^{2}}\right)
$$


When $\beta_{0}=0$, this reduces to

$$
V X=V X(0)=\Sigma_{i} X_{i}
$$

where $V \dot{X}_{i}$ is the variance of the doses in the $\mathrm{i}^{\text {th }}$ risk set.

Suppose now that only measured doses $\mathrm{z}$ are available. In this case, inferences would usually be based on the statistics given in Equations (1) and (2), but measured doses would be substituted for true doses. It is shown in the Appendix and by Gilbert (1988) that the asymptotic relative efficiency (ARE) of the statistic based on this substitution, relative to the comparable statistic based on true doses for testing the null hypothesis $\beta=0$, is given by $R=V X / V Z$, where VX is as defined above and VZ is the analogous statistic based on measured doses $z$. Thus, to evaluate the effects of the substitution of measured doses for true doses, the quantity $\mathrm{R}$ needs to be evaluated under reasonable assumptions regarding the magnitude and nature of the dose measurement errors.

To appreciate the relevance of the statistic $R$, it may be helpful to note that if the dose distributions are the same for all risk sets, and if the expectation of $\mathrm{z}$ is a linear function of $\mathrm{x}$ (including the case $\mathrm{E}(\mathrm{z} \mid \mathrm{x})=\mathrm{x})$, then $\mathrm{R}$ is the squared correlation coefficient of $\mathrm{x}$ and $\mathrm{z}$. More generally, $\mathrm{R}$ is shown in the Appendix to be a weighted mean of the squared correlation coefficients in all risk sets with the weights $\mathrm{VZ}_{\mathrm{i}}$.

It is also useful to consider the bias in the estimated risk coefficient resulting under what is often referred to as the "classical error model." In this model, the distribution of the true doses $\mathrm{x}$ is assumed to be normal with mean $\mu$ and variance $\sigma^{2}$, and the distributions of the measured doses $\mathrm{z}$ conditional on the true doses $\mathrm{x}$ are assumed to be normal with mean $\mathrm{x}$ and variance $\sigma_{\mathrm{c}}{ }^{2}$. The ratio of the variances of true and measured doses is then given by $R=\sigma^{2} /\left(\sigma^{2}+\sigma_{e}{ }^{2}\right)$, and Cochran (1965) has shown that simple linear regression based on $\mathrm{z}$ instead of $\mathrm{x}$ is biased downward by the factor $\mathrm{R}$.

Armstrong (1990) notes that the classical model can also be applied to relative risk regression when the relative risk is of the form $\exp (\beta \mathrm{x})$. Both Prentice (1982) and Armstrong (1990) note that if the classical model is applied to the linear relative risk model, the coefficient $\beta$ (ERR) would be biased downward by the factor $\mathrm{R}^{\prime}=\mathrm{R} /[1+\beta \mu(1-\mathrm{R})]$. However, for this relationship to hold, it is necessary to assume that $\sigma$ and $\mu$ do not depend on age and other stratification variables.

The classical model is not likely to apply to worker data, where the distributions of $z$ conditional on $\mathrm{x}$ often depend on $\mathrm{z}$, and where the distributions of true doses are highly skewed and depend strongly on age and other factors. Nevertheless, this model demonstrates the general relevance of the ratio of the variances of true and measured doses $(R)$ for quantifying the effects of dose measurement error on dose-response analyses. 


\subsection{Approach for Evaluating the Statistic R, and Specification of Models for Error Distributions}

In this section, the approach for evaluating the statistic $\mathrm{R}=\mathrm{VX} / \mathrm{VZ}$ for the Hanford data is . described. First, variances associated with actual risk sets from analyses of Hanford cancer mortality data are used to evaluate VZ. Specifically, VZ is evaluated based on the doses in the risk sets for 1426 cancer deaths occurring in the Hanford worker study population, excluding workers who had confirmed internal intakes of radionuclides or who received a substantial portion of their dose from neputrons or from low-energy photons $(<100 \mathrm{keV})$. The exposure measure used in these calculations is the cumulative dose up to 10 years prior to the time at risk, and the follow-up period is 1945-86. Details regarding the Hanford study population and the stratification variables used to define risk sets are given by Gilbert et al. (1993b). The method used to identify the excluded workers is described by Gilbert and Fix (1995).

To develop an approach for evaluating VX, it is first noted that for any two random variables $\mathrm{x}$ and $z, \operatorname{Var}(z)=\operatorname{Var}(x)+E_{x} \operatorname{Var}(z \mid x)$, provided $E(z \mid x)=x$, where $E(z \mid x)$ is the expected value of $z$ conditional on $x$ and $E_{x} \operatorname{Var}(z \mid x)$ is the expected value of $\operatorname{Var}(z \mid x)$ over the distribution of $x$. Using the risk sets for Hanford workers and the notation indicated for Equations (3) and (4) gives the following equation for $\mathrm{VZ}_{\mathbf{i}}$ :

$$
\mathrm{VZ}_{\mathrm{i}}=\mathrm{VX}_{\mathrm{i}}+\mathrm{EVZX}_{\mathrm{i}}
$$

where

$$
\operatorname{EVZX}_{i}=\Sigma_{j} \operatorname{Var}_{i j}\left(Z_{i j} \mid x_{i j}\right) / N_{i}
$$

To evaluate $\mathrm{EVZX}_{\mathrm{i}}$, and subsequently to evaluate the $\mathrm{VX}$ and $\mathrm{VX}$, models are needed to describe the magnitude and nature of random errors in estimated doses resulting from sampling variation inherent in processing dosimeters. Unlike errors from many other sources, it is appropriate to assume that these laboratory errors are independent both for measurements from different workers and for different measurements for the same workers.

The following notation is needed, and refers to dosimetry for a single worker. Let u denote the true dose associated with a single dosimeter reading, and let $\mathrm{v}$ denote the corresponding measured dose. When referring to specific doses in specific years, the following notation is also used. Let $u_{k \ell}$ denote the true dose associated with reading $\ell$ in year $\mathrm{k}$, and let $\mathrm{v}_{\mathrm{kl}}$ denote the corresponding measured

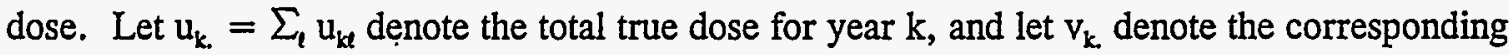


measured dose. Finally, let $x=\sum_{k} u_{k}$ denote the true cumulative dose, and $z$ denote the corresponding measured cumulative dose. These cumulative doses depend on the lag period and the age or time at risk.

The models for laboratory measurement error are specified in terms of the mean and variance of the distribution of the measured doses (v) conditional on the true doses (u). In all cases, it is assumed that the measured dose $v$ is an unbiased estimate of $u$ : that is, $E(v \mid u)=u$. Three models are considered for the variances of $v$ conditional on $u$. Under model $1, \operatorname{Var}(v \mid u)$ is independent of the value of $u$ and equals $K 1^{2}$. Under model 2, the variance is proportional to $u$ with $\operatorname{Var}(v / u)=K 2^{2} u$. Under model 3, the standard deviation is proportional to $\mathrm{u}$ so that $\operatorname{Var}(\mathrm{v} \mid \mathrm{u})=\mathrm{K} 3^{2} \mathrm{u}^{2}$. Based on the assumption that readings are independent, expressions can be developed for the variance of annual and cumulative doses, and these are shown in Table 4.1.

The expressions in the third column of Table 4.1 (for cumulative doses) can be used to evaluate the EVZX $_{i}$ in Equation (6). For model 1,

$$
\operatorname{EVZX}_{\mathrm{i}}=\mathrm{K} 1^{2} \Sigma_{\mathrm{j}} \mathrm{m}_{\mathrm{j} .} / \mathrm{N}_{\mathrm{i}}
$$

where $m_{j}$ is the total number of dosimeters contributing to the dose estimate for worker $j$ in risk set $I$. For model 2,

$$
\operatorname{EVZX}_{\mathrm{i}}=\mathrm{K} 2^{2} \Sigma_{\mathrm{j}} \mathrm{x}_{\mathrm{ij}}
$$

Table 4.1. Variance of the Measured Doses Conditional on the True Doses for Individual Dosimeter Readings, Annual Doses, and Cumulative Doses

\begin{tabular}{|c|c|c|c|}
\hline Model & $\begin{array}{l}\text { Individual Dosimeter } \\
\text { Reading }^{(a)}\end{array}$ & Annual dose $\mathrm{e}^{(\mathrm{b})}$ & $\begin{array}{c}\text { Cumulative } \\
\text { Dose }^{(\mathfrak{c})}\end{array}$ \\
\hline 1 & $\mathrm{~K} 1^{2}$ & $\mathrm{~K} 1^{2} \mathrm{~m}_{\mathrm{k}}$ & $\mathrm{K}^{2} \sum_{\mathrm{k}} \mathrm{m}_{\mathrm{k}}$ \\
\hline 2 & $\mathrm{~K} 2^{2} \mathrm{u}_{\mathrm{kl}}$ & $\mathrm{K}^{2}{ }^{2} \mathrm{u}_{\mathrm{k}}$ & $\mathrm{K}^{2} \mathrm{x}$ \\
\hline \multirow[t]{2}{*}{3} & $K 3^{2} u_{k t}{ }^{2}$ & $\mathrm{~K}^{2} \sum^{2} \mathrm{u}_{\mathrm{k} \ell}{ }^{2}$ & $\mathrm{~K}^{2}{ }^{2} \sum_{\mathrm{l}} \sum_{\mathrm{k}} \mathrm{u}_{\mathrm{kl}}{ }^{2}$ \\
\hline & & $\leq \mathrm{K} 3^{2} \mathrm{u}_{\mathrm{k} .}{ }^{2}$ & $\leq K 3^{2} \sum_{k} u_{k}^{2}$ \\
\hline \multicolumn{4}{|c|}{$\begin{array}{l}\text { (a) The true dose associated with reading } \ell \text { in year } k \text { is denoted by } u_{k \ell} \cdot \\
\text { (b) } m_{k} \text { is the number of dosimeter readings in year } k \text {; the total true } \\
\text { dose for year } k \text { is denoted by } u_{k}=\sum_{\ell} u_{k \ell} \text {. } \\
\text { (c) The true cumulative dose is denoted by } x=\Sigma_{k} u_{k} \text {. }\end{array}$} \\
\hline
\end{tabular}
for an Individual Worker 
Because $E(z \mid x)=x$, it is reasonable to substitute $z_{i j}$ for $x_{i j}$ in evaluating this expression, where the $z_{i j}$ are obtained from the actual Hanford risk sets. For model 3 ,

$$
\operatorname{EVZX}_{\mathrm{i}}=\mathrm{K} 3^{2} \Sigma_{\mathrm{j}} \Sigma_{\mathrm{k}} \Sigma_{\ell} \mathrm{u}_{\mathrm{ijk \ell}}
$$

where $u_{\mathrm{ijk}}$ is the true dose for the $\ell^{\text {th }}$ dosimeter reading in the $\mathrm{k}^{\text {th }}$ year for worker $\mathrm{j}$ in risk set $\mathrm{i}$. Since $\mathrm{E}\left(\mathrm{v}_{\mathrm{ijk \ell}}{ }^{2} \mid \mathrm{u}_{\mathrm{ijk \ell}}\right)=\left(\mathrm{K}^{2}+1\right) \mathrm{u}_{\mathrm{ijkl}}{ }^{2}$, it is reasonable to substitute $\mathrm{v}_{\mathrm{ijk \ell}}{ }^{2} /\left(\mathrm{K} 3^{2}+1\right)$ for the true $\mathrm{u}_{\mathrm{ijk \ell}}{ }^{2}$.

A difficulty in evaluating these expressions is that the computerized Hanford database includes only information on annual doses and does not include the individual dosimeter results that are required for model 3, or the number of dosimeter results on which annual doses are based required for model 1. For model 1, general information on the frequency of monitoring in various calendar years can be used to obtain reasonable values for the $m_{j}$. For model $3, \Sigma_{l} v_{k l}{ }^{2} \leq v_{k}{ }^{2}$, so that a maximum value can be obtained by substituting $v_{k}{ }^{2}$ for $\Sigma_{l} v_{k \ell}{ }^{2}$. This approach may also serve to accommodate certain laboratory uncertainties that may not be completely independent for different readings, but may be reasonably independent if annual doses are considered. Alternatively, one can make use of the fact that individual dosimeter results for Hanford workers rarely exceed $5 \mathrm{mSv}$; for example, for an annual dose of $23 \mathrm{mSv}$, the value $4\left(5^{2}\right)+3^{2}$ might be conservatively used as a substitute for the sum of the squares of the individual dosimeter readings in evaluating model 3.

For occupational doses that are either zero or very close to background levels, models 2 and 3 undoubtedly underestimate the variance. For this reason, some calculations have been made in which the variance from these models is added to that from model 1. Model 1 is based on the assumption that all doses are recorded exactly as measured, including the recording of negative doses for instances in which the observed dose is less than the background dose. In practice, negative doses are recorded as zero. In some situations, positive values below some specified "minimum detectable level" have also been recorded as zero (Inskip et al. 1987, Kerr 1994), although there is no evidence that this was done at Hanford (Gilbert 1990). These procedures would tend to decrease the variance of the estimated dose, and thus the expressions in Table 4.1 slightly overestimate variances: These procedures also introduce bias; the effects of such bias on dose-response analyses have been evaluated by Gilbert and Fix (1995) for the Hanford study and by Inskip et al. (1987) for a United Kingdom worker study.

Ideally, the choice of models and of the constants $\mathrm{K} 1, \mathrm{~K} 2$, or $\mathrm{K} 3$ should be based on data evaluating the sampling errors involved in reading dosimeters and the dependence of these errors on the magnitude of the exposure. For this reason, technical reports describing Hanford dosimetry systems in use at various times have been reviewed, and a summary of the results of this review, including plausible values for $K 1, K 2$, and $K 3$, is given in Section 5.0.

Unfortunately, available reports and data do not provide clearcut answers regarding the nature and magnitude of the laboratory measurement error in Hanford doses as measured in various time periods. Our approach is thus to make calculations based on all three models shown in Table 4.1, and on a 
range of values of the constants $\mathrm{K} 1, \mathrm{~K} 2$, and $\mathrm{K} 3$, giving consideration to the results of our review. In the introduction, it was conjectured that the effects of laboratory measurement errors on dose-response analyses would be small. For this reason, error models that clearly overestimate error have been included. If it can be established that large errors do not distort dose-response analyses, then smaller errors will not do so either. 


\subsection{Review of Materials Relevant to Quantifying Laboratory Measurement Errors in Hanford Worker Dosimetry}

In the review that follows, results have been converted from their original units to $\mathrm{mSv}$, a currently accepted measure of deep dose equivalent. Most of the reports discussed in this section present results in terms of exposure expressed in Roentgen (R) or milli-Roentgen (mR). For the high energy photon radiation of interest for this report, $1 \mathrm{mSv}$ is approximately equal to $0.1 \mathrm{R}$ or $100 \mathrm{mR}$.

A committee of the National Research Council (NRC) developed an approach for quantifying bias and uncertainty in dose estimates obtained from film badge readings for military personnel exposed to radiation as a resült of atmospheric testing of nuclear weapons between 1945 and 1962 (NAS/NRC 1989). Although the NRC committee evaluated uncertainties from several sources, it gave special attention to laboratory uncertainties, where available data and theoretical considerations could be used to obtain a more rigorous evaluation than for other sources.

The quantity actually measured with the use of film badges is the optical density (OD). To estimate dose, a calibration curve must be established. This is accomplished by exposing several film badges to each of several known exposures, and then fitting an appropriate curve, often referred to as the characteristic function. The use of replicate badges at the same exposure allows the estimation of the standard deviation associated with a particular measurement. This form of error is referred to in this report as "intrinsic" laboratory or sampling error.

The functional form for expressing the optical density as. a function of dose or exposure is given by

$$
O D=O D_{\infty}\left(1-e^{-\gamma u}\right)
$$

where $O D$ is the optical density, $u$ is the dose in $\mathrm{mSv}_{\mathrm{O}} \mathrm{OD}_{\infty}$ is the saturation density of the film at high exposures, and $\gamma$ is the sensitivity of the film. For the Du Pont Type 502 film used in many of the atmospheric test series, $\mathrm{OD}_{\infty}=2.8$ and $\gamma=0.025$.

Based on the above relationship of $O D$ and $u, O D$ is approximately equal to $O D_{\infty} \gamma u$ for small values of $\gamma u$. For. $\gamma$ in the range of 0.025 , this relationship provides a reasonable approximation for doses less than $5 \mathrm{mSv}$. Review of detailed dosimetry data for Hanford workers (Gilbert 1990) indicates that results from individual dosimeters rarely exceeded $5 \mathrm{mSv}$. Although results shown in reports that were reviewed were sometimes given in OD units, for this report, these have been converted to dose (in $\mathrm{mSv}$ ) using the above approximation.

Examination of available calibration data associated with test participant dosimetry indicated that the standard deviation of the measured optical densities did not depend strongly on the magnitude of the 
exposure and was approximately equal to 0.015 . For the values of $O D_{\infty}$ and $\gamma$ given above, $O D$ is approximately equal to $0.07 \mathrm{u}$, and the standard deviation of the measured exposures is approximately equal to $0.015 / 0.07$ or $0.2 \mathrm{mSv}$, which can be taken as the appropriate value of $\mathrm{K} 1$ for test participant dosimetry.

Although the standard deviation of $0.2 \mathrm{mSv}$ was intended to apply only to intrinsic variation about the calibration curve, the NRC committee included under the category of laboratory uncertainties

all uncertainties introduced in film calibration, chemical processing of films, reading their optical densities, comparing these densities with the densities of unexposed and calibration films, and in interpreting the measured densities in term of exposure.

The committee further notes that

the intrinsic uncertainties in determining exposure discussed above are increased by uncertainties in the radiation field and in the time used in calibration, by variations in film processing conditions if calibration and unexposed films are not processed with each batch of field exposed film badges, and by possible inaccuracies in reading a calibration curve.

Because this definition involves other uncertainties than the intrinsic laboratory error described above, the NRC judged that with a lognormal uncertainty distribution, which is an example of model 3 , the minimum uncertainty would be expressed by a geometric standard deviation of about 1.1 for most atmospheric tests, or $\mathrm{K} 3=0.1$. The $\mathrm{NRC}$ model also allowed for additional uncertainty for exposures less than $2 \mathrm{mSv}$ in acçordance with the standard deviation of $0.2 \mathrm{mSv}$. It is probably reasonable to assume that errors from laboratory sources other than intrinsic error are reasonably independent across time, at least for annual dose estimates.

To evaluate appropriate error models for Hanford dosimetry, material describing dosimeters used at Hanford has been reviewed. Baumgartner (1960) presents calibration data for the $502 \mathrm{film}$, used at Hanford from 1944 to 1957, and Wilson and Larson (1961) present such data for the 508 film, used at Hanford from 1957 to 1965. In addition, data from a laboratory intercomparison of all Hanford film badge dosimeters, conducted in 1989, were evaluated (Wilson et al. 1990). Because the follow-up period for Hanford workers extends only through 1986 and because most analyses were based on a 10-year lag period, it is primarily dosimetry prior to 1972 when film badges were in use that is of current interest. For completeriess and for future use, a report by Beetle et al. (1972) on the thermoluminescent dosimeter, used from 1972 to the present, is also reviewed.

Baumgartner (1960) conducted experiments in which fifty 502 films were exposed to doses of 0 , $0.35,0.7,1$, and $2 \mathrm{mSv}$. These data confirm the relationship OD $=0.07 \mathrm{u}$, with standard deviations of the optical density ranging from 0.002 to 0.005 . The Baumgartner standard deviations expressed in $\mathrm{mSv}$ range from about 0.03 to 0.07 . The standard deviations tended to increase in proportion to the exposure, and our calculations indicated that a value of $\mathrm{K} 3=0.022$ described the data reasonably well. 
The Baumgartner standard deviations are much smaller than the $0.2 \mathrm{mSv}$ value used by the NRC committee for nuclear test participants, probably because the data were from a carefully controlled laboratory-based study in which films from a single production batch of film were processed at one time. Thus, the Baumgartner values may not be representative of the laboratory errors associated with usual dosimetry practices used for radiation protection.

Wilson and Larson (1961) evaluated the 508 film by exposing 10 films at each of 30 doses ranging from $0.015 \mathrm{mSv}$ to $100 \mathrm{mSv}$. For the 11 doses in the range $0.5 \mathrm{mSv}$ to $5 \mathrm{mSv}$, our calculations indicate that the relationship of standard deviation to dose is well characterized by model 2 with a value of $\mathrm{K} 2$ of about 0.10 for dose measured in mSv. Values of $D_{\infty}=2.8$ and $\gamma=0.035$ described the relationship of dose in $\mathrm{mSv}$ and the net optical density. The standard deviations ranged from 0.05 to $0.23 \mathrm{mSv}$ for doses of 0.5 to $5 \mathrm{mSv}$.

We have interpreted the results in Wilson and Larson as standard deviations, although the report does not make it entirely clear whether they actually reflect standard deviations or standard errors. If, in fact, they are standard errors, then the values of the standard deviations and of $\mathrm{K} 2$ would need to be increased by a factor of 3.16 (the square root of 10 ). These alternative results are shown in a footnote to Table 5.1 and seem unduly large relative to other values presented.

The 1989 intercomparison study (Wilson et al. 1990) included evaluation of all types of film dosimeters used at Hanford from 1944 to the present. The results shown in Table 5.1 are based on analyses of the original data on exposure to high-energy photons $\left({ }^{137} \mathrm{Cs}\right)$ using dosimeters representing the periods 1945-56 and 1957-71. The estimated standard deviations for the earlier period were 0.023, $0.024,0.18$, and $0.20 \mathrm{mSv}$ for exposures of $0.5,2.5,7.5$, and $10 \mathrm{mSv}$, respectively. For the later period, the estimated standard deviations were $0.023,0.057,0.16$, and 0.22 for these same respective exposure levels. For the range of greatest interest $(<5 \mathrm{mSv})$, these standard deviations are much smaller than the value of 0.2 used in the NAS report. It should be noted that each exposure level included only five replications and, thus, the estimated standard deviations are not very precise. The data suggest that model 3 is reasonably appropriate for exposures of $2.5 \mathrm{mSv}$ and above, with $\mathrm{K} 3$ about 0.023. As with the Baumgartner (1960) study, these values may be smaller than those associated with usual dosimetry practices during the time periods the dosimeters were in use.

Unruh et al. (1967) review data from several dosimeter processors and use these data to establish film dosimeter performance criteria. Unruh et al. judged that model 2 was most appropriate for highenergy photons and proposed a value of $\mathrm{K} 2=0.15$ for dose measured in $\mathrm{mSv}$, a value that is a little larger than the value of 0.10 based on data from Wilson and Larson (1961). The $\mathrm{K} 2$ value was derived as a value that would allow the more competent film badge processors to "pass" variance criteria.

A multipurpose five-chip thermoluminescent dosimeter was implemented at Hanford on January 1, 1972, following earlier implementation of a one-chip thermoluminescent dosimeter on January 1, 1971. Several studies of the Hanford thermoluminescent dosimeter system have been conducted (Kocher et al. 1972, Fix et al. 1981, 1982). Beetle (1972) describes experiments conducted to evaluate the performance of the one-chip dosimeter. These include replicate dosimeter data for nine exposure levels 
Table 5.1. Summary of Information on Error Coefficients (K1, K2, K3) from Several Reports ${ }^{(a)}$

\begin{tabular}{|c|c|c|c|}
\hline Report & Model 1 (K1) & $\begin{array}{c}\text { Model } 2 \\
\text { (K2) }\end{array}$ & Model 3 (K3) \\
\hline $\begin{array}{l}\text { NAS/NRC (1989) } \\
\text { Baumgartner (1960) }\end{array}$ & $\begin{array}{c}0.2 \\
0.03-0.07\end{array}$ & - & $\begin{array}{l}0.1 \\
0.022\end{array}$ \\
\hline Wilson and Larson $(1961)^{(\mathbf{b})}$ & $0.05-0.23$ & 0.10 & - \\
\hline $\begin{array}{l}\text { Wilson et al. (1990) } \\
1957 \text { dosimeter } \\
1962 \text { dosimeter }\end{array}$ & $\begin{array}{c}0.023 \\
0.023-0.057\end{array}$ & - & 0.023 \\
\hline Unruh et al. (1967) & & 0.15 & - \\
\hline Beetle et al. (1972) & $0.12-0.59$ & - & 0.1 \\
\hline \multicolumn{4}{|c|}{$\begin{array}{l}\text { (a) Applicable to doses of } 5 \mathrm{mSv} \text { or less for individual dosimeters. } \\
\text { (b) The values presented are based on interpreting results in Wilson and Larson } \\
\text { as standard deviations. If they are interpreted as standard errors, the } \mathrm{K} 1 \\
\text { values would range from } 0.17 \text { to } 0.73 \text {, and the } \mathrm{K} 2 \text { value would be } 0.32 \text {. See } \\
\text { text for further discussion. }\end{array}$} \\
\hline
\end{tabular}

ranging from 0 to $12 \mathrm{mSv}$, with 15 observations at each level. These data, which are indicative of the performance of either the one-chip or the five-chip dosimeter system for higher-energy photon radiation, show standard deviations ranging from 0.12 to $0.59 \mathrm{mSv}$ for doses ranging from 0.5 to $6 \mathrm{mSv}$. Model 3 with $\mathrm{K} 3=0.1$ fitted the data quite well.

Subsequently, several improvements to the thermoluminescent system have been implemented, including the use of individual radiation sensitivity factors for each dosimeter. Thus, later data are more precise than indicated by the 1972 data from Beetle. For example, examination of monthly audit data from 1996 indicate standard deviations of 0.02 to 0.05 for the 1-2 mSv range.

The results discussed above are summarized in Table 5.1. 


\subsection{Results}

Table 6.1 shows values of $1-\mathrm{R}$ for each of the three models and for a range of values of $\mathrm{K} 1, \mathrm{~K} 2$ and K3. In applying model 1, it was assumed that each annual recorded dose from years before 1958 was based on 52 film badges, and that each recorded dose from years 1958 and later was based on 12 film badges. Because monitoring was biweekly for some years prior to 1958 and because in later years some workers (those with limited potential for exposure) were monitored quarterly or yearly, these values probably slightly overestimate the errors associated with model 1 . Because the individual dosimeter results needed to evaluate model 3 were not available in computerized form, two approaches were used for this model; these are described in the text above and in the footnotes to Table 6.1. Approach A provides an upper bound for 1-R, while approach B provides a somewhat more realistic estimate although it is also likely to overestimate $1-R$.

In virtually all cases, the values of $1-R$ are very small, indicating that $R$ is very close to 1 and that random measurement error has very little effect on dose-response analyses. For model 1, 1-R is less than $1 \%$, provided that $\mathrm{K} 1$ is less than 0.2 , the maximum value indicated in Table 5.1 for film badges. ${ }^{\text {(a) }}$ For model $2,1-\mathrm{R}$ is less than $1 \%$, even with a $\mathrm{K} 2$ value of 1 , i.e., 10 times the value calculated from Wilson and Larson (1961). For model 3 and approach A, 1-R is less than 1\%, provided that $K 3$ is less than 0.3 , a value 3 times that used in the NAS/NRC study (1989). With approach $\mathrm{B}, 1-\mathrm{R}$ is less than $1 \%$, provided that $\mathrm{K} 3$ is less than 0.5 .

Models 2 and 3 are likely to underestimate errors for workers with small recorded doses, and model 1 may underestimate errors for workers with larger doses. For a conservative evaluation, it is worth considering the sum of errors from model 1 , with the large $\mathrm{K} 1(=0.2)$ from the NAS/NRC stidy (1989), and errors from model 3/approach $A$ with a $K 3$ value of 0.2 , twice the NAS/NRC value. These very conservative assumptions result in a total $1-R$ value of about $1 \%$. If values of $R$ (or $1-R$ ) are desired for other $\mathrm{K} 1, \mathrm{~K} 2$, or $\mathrm{K} 3$ values (or combinations), these can be easily calculated using the multipliers shown in the second line of Table 6.1 .

The calculations shown in Table 6.1 were based on the risk sets associated with the 1426 cancer . deaths in Hanford workers, excluding workers with confirmed internal intakes or potential for neutron exposure.

(a) The thermoluminescent dosimeter shows standard deviations as large as 0.6 for exposures in the range of $5 \mathrm{mSv}$. However, the value of 1-R shown in Table 6.1 for $\mathrm{K} 1=0.6$ is based on the assumption that all dosimeters had standard deviations of this magnitude (not just those with exposures in the $5 \mathrm{mSv}$ range). Furthermore, 52 dosimeters per year were assumed for the period 1944-1957, a situation that never occurred with the TLD. If 12 dosimeters per year are assumed for all years, the value of $1-\mathrm{R}$ would be $0.0462 \mathrm{~K}^{2}$ instead of $0.1408 \mathrm{~K} 1$; $^{2}$ that is, $1-\mathrm{R}$ would be reduced by a factor of 3 . 
Table 6.1. Values of 1-R for Several Values of $\mathrm{K} 1, \mathrm{~K} 2, \mathrm{~K} 3$ Based on Cancer Mortality Data for Hanford Workers Excluding Workers with Confirmed Internal Intakes or with Potential for Neutron Exposure. Doses Lagged by 10 Years.

\begin{tabular}{|c|c|c|c|c|c|c|}
\hline & & & & & Mo & \\
\hline & del 1 & & del 2 & App & $\operatorname{ach} A^{(a)}$ & Approach $\mathbf{B}^{(\mathbf{b})}$ \\
\hline & $08 \mathrm{~K}^{2}$ & 0.00 & $28 \mathrm{~K}^{2}$ & 0.1 & $18 \mathrm{~K}^{2}$ & $0.03538 \mathrm{K3}^{2}$ \\
\hline $\mathrm{K} 1$ & $1-R$ & $\mathrm{~K} 2$ & $1-R$ & $\mathrm{~K} 3$ & $1-R$ & $1-R$ \\
\hline 0.01 & $<10^{-4}$ & $0: 05$ & $<10^{-4}$ & 0.02 & $<10^{-4}$ & $<10^{-4}$ \\
\hline 0.02 & $<10^{-4}$ & 0.10 & $<10^{-4}$ & 0.05 & 0.00031 & $<10^{-4}$ \\
\hline 0.03 & 0.00013 & 0.15 & 0.00020 & 0.10 & $0.0012^{\circ}$ & 0.00035 \\
\hline 0.04 & 0.00023 & 0.20 & 0.00036 & 0.20 & 0.0050 & 0.0014 \\
\hline 0.05 & 0.00035 & 0.30 & 0.00080 & 0.30 & 0.011 & 0.0032 \\
\hline 0.10 & 0.0014 & 0.40 & 0.0014 & 0.40 & 0.020 & 0.0057 \\
\hline 0.20 & 0.0056 & 0.50 & 0.0022 & 0.50 & 0.031 & 0.0088 \\
\hline 0.40 & 0.023 & 0.75 & 0.0050 & 0.75 & 0.070 & 0.020 \\
\hline 0.60 & 0.051 & 1.00 & 0.0089 & 1.00 & 0.125 & 0.035 \\
\hline $\begin{array}{l}\text { (a) } \mathrm{Ba} \\
\\
\text { (b) } \\
\text { (ba } \\
\text { in }\end{array}$ & $\begin{array}{l}\text { on the si } \\
\mathrm{d} \text { sum of } \\
\text { on the } \mathrm{n} \\
\text { dual dosi } \\
\mathrm{mSv} \text {, the }\end{array}$ & $\begin{array}{l}\text { ed ar } \\
\text { squa } \\
\text { num } \\
\text { r res } \\
\text { ressi }\end{array}$ & $\begin{array}{l}\text { dose. T } \\
\text { f the ind } \\
\text { of squar } \\
\text { exceed } 5 \\
\left(5^{2}\right)+3^{2} \\
\end{array}$ & $\begin{array}{l}\text { appr } \\
\text { dual } \\
\text { under } \\
\text { Sv. } \\
\text { ould }\end{array}$ & $\begin{array}{l}\text { a will ove } \\
\text { neter rest } \\
\text { assumpt } \\
\text { example, } \\
\text { sed. }\end{array}$ & $\begin{array}{l}\text { stimate the } \\
\text { that no } \\
\text { an annual dose }\end{array}$ \\
\hline
\end{tabular}

Doses were lagged for 10 years in these calculations. Calculations were also made for all cancer excluding leukemia, for a 2-year lag for all cancer, for all cancer excluding leukemia, and for leukemia excluding chronic lymphatic leukemia (CLL): In addition; calculations were made without excluding workers with confirmed internal intakes or potential for neutron exposure. Table 6.2 gives results of these alternative calculations by showing the multipliers of $\mathrm{K}^{2}, \mathrm{~K}^{2}$, or $\mathrm{K} 3^{2}$ needed to obtain $1-\mathrm{R}$, with the first line showing the values upon which Table 6.1 was based. All these approaches gave similar results to those shown in Table 6.1, although results based on a 2-year lag gave slightly lower values, probably because cumulative doses with a 2 -year lag are often based on more dosimeters than cumulative doses with a 10 -year lag. 
Table 6.2. Expressions for $1-R$ Based on Alternative Treatments of Hanford Mortality Data

\begin{tabular}{|c|c|c|c|c|}
\hline Approach & Model 1 & Model 2 & $\begin{array}{c}\text { Model 3 } \\
\text { (Approach A) }\end{array}$ & $\begin{array}{l}\text { Number of } \\
\text { Deaths }\end{array}$ \\
\hline \multicolumn{5}{|l|}{$\begin{array}{l}\text { Hanford study population; } \\
857 \text { workers excluded;(a) } \\
\text { doses lagged by } 10 \text { years. }\end{array}$} \\
\hline All cancer & $0.1408 \mathrm{~K}^{2}$ & $0.00893 \mathrm{~K} 2^{2}$ & $0.1248 \mathrm{~K}^{2}$ & 1426 \\
\hline $\begin{array}{l}\text { All cancer excluding } \\
\text { leukemia }\end{array}$ & $0.1435 \mathrm{~K} 1^{2}$ & $0.00901 \mathrm{~K} 2^{2}$ & $0.1256 \mathrm{~K}^{2}$ & 1374 \\
\hline \multicolumn{5}{|l|}{$\begin{array}{l}\text { Hanford study population; } \\
857 \text { workers excluded; } \\
\text { doses lagged by } 2 \text { years. } \\
\end{array}$} \\
\hline All cancer & $0.0973 \mathrm{~K}^{2}$ & $0.00725 \cdot \mathrm{K}^{2}$ & $0.1084 \mathrm{~K}^{2}{ }^{2}$ & 1426 \\
\hline $\begin{array}{l}\text { All cancer excluding } \\
\text { leukemia }\end{array}$ & $0.0986 \mathrm{~K}^{2}$ & $0.00729 \mathrm{~K} 2^{2}$ & $0.1089 \mathrm{~K}^{2}$ & 1374 \\
\hline $\begin{array}{l}\text { Leukemia excluding } \\
\text { chronic lymphatic } \\
\text { leukemia }\end{array}$ & $0,0707 \mathrm{~K} 1^{2}$ & $0.00646 \mathrm{~K} 2^{2}$ & $0.1010 \mathrm{~K}^{2}$ & 43 \\
\hline \multicolumn{5}{|l|}{$\begin{array}{l}\text { Hanford study population; } \\
\text { all workers; doses lagged } \\
\text { by } 10 \text { years. }\end{array}$} \\
\hline All cancer & $0.1129 \mathrm{~K}^{2}$ & $0.00832 \mathrm{~K} 2^{2}$ & $0.1245 \mathrm{~K}^{2}$ & 1466 \\
\hline $\begin{array}{l}\text { All cancer excluding } \\
\text { leukemia }\end{array}$ & $0.1147 \mathrm{~K}^{2}$ & $0.00837 \mathrm{~K} 2^{2}$ & $0.1251 \mathrm{~K}^{2}$ & 1413 \\
\hline
\end{tabular}




\subsection{Discussion}

Estimates of external dose obtained from personal dosimeters are subject to several sources of error. An NRC/NAS Committee (1989) has described these sources in the context of film badge dosimetry in atmospheric nuclear tests, and Fix et al. (1994) and Gilbert et al. (1996) have described sources of error in external dosimetry for Hanford workers. The most obvious and best known source of error-from laboratory measurements-results from the intrinsic sampling variability in reading film badges and thermoluminescent dosimeters. For dose estimates based on a single dosimeter reading, this source of error is likely to predominate, especially if the dose is small. Often, estimates of error that are shown for film and thermoluminescent readings reflect primarily errors from this source.

This report addresses dose estimates as they are used in epidemiologic dose-response analyses. For this purpose, it is dose that is accumulated over a period of years that is of interest, with larger cumulative doses playing a particularly influential role. Because larger cumulative doses are the sum of results from many different dosimeter readings, and because laboratory errors can be assumed to be independent for measurements at different times, the relative error in such doses is likely to be small. This led to the conjecture that the presence of laboratory error is unlikely to seriously distort doseresponse analyses.

The results shown in this report have demonstrated that this conjecture is correct, at least for analyses of cancer mortality in Hanford workers. Specifically, it has been demonstrated that, even when assumptions are made that almost certainly overestimate the magnitude of laboratory errors, the increase in the total variance (summed over all risk sets) of the measured doses is unlikely to be more than $1 \%$ of the total variance of the true doses. It has also been shown that for the linear relative risk model, the ratio of the variances of the true and estimated doses can be interpreted as the asymptotic relative efficiency (ARE) of a test of the null hypothesis based on the measured doses relative to a test based on the true doses, and can also be interpreted as a weighted mean over all risk sets of the squared correlation coefficient of the true and measured doses. Furthermore, others have shown that the ratio $R$ is related to the bias in risk coefficients based on measured instead of true dose estimates (Cochran 1965, Armstrong 1990). Our results, therefore, indicate that laboratory measurement error should lead to almost no distortion in results in that the bias, squared correlation coefficient, and the ARE are likely to be in the range 0.99 to 1 .

It is important to note that the above conclusion applies only to errors that are independent both across time and across workers. Laboratory sampling error may be the only type of error that rigorously meets these criteria although certain other types of laboratory error (resulting from variation in the calibration curve and problems other than sampling error) may be approximately independent, at least for annual doses.

Fix et al. (1994) and Gilbert et al. (1996) identify several sources of error that result primarily from the inability of dosimeters to respond accurately to all radiation energies to which workers are exposed or to radiation coming from all directions. Because workers may tend to work in the same 
exposure environment for extended periods, it is not reasonable to assume that these errors are independent across time. Unlike laboratory measurement error, errors from these other sources may thus have the potential for distorting dose-response analyses. These errors have been quantified for Hanford workers, and some efforts have been made to examine their effects on dose-response analyses (Gilbert 1995a).

In addition, several sources of potential bias in dose estimates are discussed by Gilbert and Fix (1995). This report does not address these biases, but sensitivity analyses conducted by Gilbert and Fix indicate that, for the Hanford data, these biases are unlikely to seriously distort results.

This report also provides a review of reports that are relevant to quantifying laboratory measurement error in Hanford worker dosimetry. Results from the experiments described in these reports are not fully consistent, and it was thus not possible to determine a single model describing laboratory error in Hanford dosimetry. Furthermore, the methods used in these experiments are not always described in detail. Thus, these reports could only be used to indicate the general magnitude of laboratory sampling errors. Fortunately, even if it was assumed that the largest observed values were the correct ones, the conclusion that laboratory error was unlikely to have distorted epidemiologic dose-response analyses remained valid.

Although the results shown in this report were based on Hanford data, the overall conclusions are likely to be relevant for other epidemiologic studies of workers exposed to external radiation. Several such studies have been carried out in the United States, the United Kingdom, and Canada (Gilbert 1995a); both national (Gilbert et al. 1993a, Carpenter et al. 1994) and international (Cardis et al. 1995) combined analyses of data from these studies have been conducted; and additional studies in several countries are currently underway (Cardis and Esteve 1992). For the international analyses, a committee of persons experienced in dosimetry and radiation protection in each of the three countries evaluated historical dosimetric practices for the facilities that were included. This committee found that dosimetry technology was very similar among the facilities. In addition, histograms shown in Cardis et al. (1995) indicate that the shapes of the dose distributions and the general magnitudes of the cumulative doses were also similar. Therefore, it seems very likely that the conclusions of this report apply to other studies, and that laboratory error is unlikely to have distorted results of other worker studies, or of the combined international analyses of workers in the U.S., U.K., and Canada.

Although errors from other sources still require attention in epidemiologic studies of workers, this report has shown that it is very unlikely that error that results from laboratory sampling variation will seriously distort results. Thus, one can safely ignore such errors and focus efforts on other sources of dosimetry errors in analyzing data from worker studies. 


\subsection{References}

Armstrong, B. 1990. "The Effects of Measurement Errors on Relative Risk Regressions." Am. J. Epidemiol. 132:1176-1184.

Baumgartner, W.V. 1960. Some Studies of Film Dosimeter Variables. HW-SA-2032, General Electric Company, Richland, Washington.

Beetle, T.M. 1972. A Probability Model for Thermoluminescent Dosimetry. BNWL-1641, Pacific Northwest National Laboratory, Richland, Washington.

Buschbom, R.L., and E.S. Gilbert. 1993. Summary of Recorded External Radiation Doses for Hanford Workers 1944-1989. PNL-8909, Pacific Northwest National Laboratory, Richland, Washington.

Cardis, E., and J. Esteve. 1992. International Collaborative Study of Cancer Risk among Nuclear Industry Workers, I-Report of the Feasibility Study, Internal Report No. 92/001, International Agency for Research on Cancer, Lyon, France.

Cardis, E., E. Gilbert, L. Carpenter, G. Howe, I. Kato, B. Armstrong, V. Beral, G. Cowper, A. Douglas, J. Fix, S، Fry, J. Kaldor, C. Lave, L. Salmon, P. Smith, G. Voelz, and L. Wiggs. 1995. "Effects of Low Doses and Low Dose Rates of External Ionizing Radiation: Cancer Mortality among Nuclear Industry Workers in Three Countries." Radiat. Res. 142:117-132.

Carpenter, L., C. Higgins, A. Douglas, P. Fraser, V. Beral, and P. Smith. 1994. "Combined Analysis of Mortality in Three United Kingdom Nuclear Industry Workforces, 1946-1988." Radiat. Res. 138:224-238.

Cochran, W.G. 1965. "Errors of Measurement in Statistics." Technometrics 10:637-665.

Fix, J.J., G.W.R. Endres, F.M. Cummings, J.M. Aldrich, M.R. Thorson, and R.L. Kathren. 1981. Hanford Personnel Dosimeter Supporting Studies FY-1980. PNL-3536, Pacific Northwest National Laboratory, Richland, Washington.

Fix, J.J., J.M. Hobbs, P.L. Roberson, D.L. Haggard, K.L. Holbrook, M.R. Thorson, and F.M. Cummings. 1982. Hanford Personnel Dosimeter Supporting Studies FY-1981. PNL-3736, Pacific Northwest National Laboratory, Richland, Washington. 
Fix, J.J., E.S. Gilbert, and W.V. Baumgartner. 1994. An Assessment of Bias and Uncertainty in Recorded Dose from External Sources of Radiation for Workers at the Hanford Site. PNL-10066, Pacific Northwest National Laboratory, Richland, Washington.

Gilbert, E.S. 1988. The Effects of Error in the Measurement of Continuous Exposure Variables on the Assessment of Risks. PNL-6578, Pacific Northwest National Laboratory, Richland, Washington.

Gilbert, E.S. 1989. "Issues in Analyzing the Effects of Occupational Exposure to Low Levels of Radiation." Statist. in Med. 8:173-187.

Gilbert, E.S. 1990. A Study of Detailed Dosimetry Records for a Selected Group of Workers Included in the Hanford Mortality Study. PNL-7439, Pacific Northwest National Laboratory, Richland, Washington.

Gilbert, E.S. 1995a. Accounting for Uncertainty in Systematic Bias in Exposure Estimates Used in Relative Risk Regression. PNL-10909, Pacific Northwest National Laboratory, Richland, Washington.

Gilbert, E.S. 1995b. "Radiation Worker Epidemiology and Risk." In Reactor Health Physics. Health Physics Society, Hershey, Pennsylvania.

Gilbert, E.S., D.L. Cragle, and L.D. Wiggs. 1993a. "Updated Analyses of Combined Mortality Data on Workers at the Hanford Site, Oak Ridge National Laboratory, and Rocky Flats Weapons Plant." Radiat. Res. 136: 408-421.

Gilbert, E.S., S.A. Fry, L.D. Wiggs, G.L. Voelz, D.L. Cragle, and G.R. Petersen. 1990. "Methods for Analyzing Combined Data from Studies of Workers Exposed to Low Doses of Radiation." $A m$. J. Epidemiol. 131:917-927:.

Gilbert, E.S., and J.J. Fix. 1995. "Accounting for Bias in Dose Estimates in Analyses of Data from" Nuclear Worker Studies." Health Phys. 68:650-660.

Gilbert, E.S., J.J. Fix, and W.V. Baumgartner. 1996. "An Assessment of Bias and Uncertainty in Recorded Dose from External Sources of Radiation for Workers at the Hanford Site." Health Phys. 70:336-345.

Gilbert, E.S., E. Omohundro, and J.A. Buchanan. 1993b. "Mortality of Workers at the Hanford Site: 1945-1986." Health Phys. 64:577-590.

Inskip, H., V. Beral, P. Fraser, M. Booth, D. Coleman, and A. Brown. 1987. "Further Assessment of the Effects of Occupational Radiation Exposure in the United Kingdom Atomic Energy Authority Mortality Study." Br. J. Ind. Med. 44:149-160. 
Kendall, M.G., and A. Stuart. 1979. In The Advanced Theory of Statistics, Vol. 2, pp. 265-67. 4th ed. MacMillan, New York.

Kerr G:D. 1994. "Missing Dose from Mortality Studies of Radiation Effects among Workers at Oak Ridge National Laboratory." Health Physics 66(2):206-208.

Kocher, L.F., G.W.R. Endres, L.L. Nichols, D.B. Shipler, and A.J. Haverfield. 1971. The Hanford Thermoluminescent Multipurpose Dosimeter. BNWL-SA-3955, Pacific Northwest National Laboratory, Richland, Washington.

National Academy of Science (NAS), National Research Council (NRC). 1989. Film Badge Dosimetry in Atmospheric Tests. , National Academy Press., Washington, D.C.

Prentice, R.L. 1982. "Covariate Measurement Errors and Parameter Estimation in Cox's Failure Time Regression Model." Biometrika 69:331-342.

Unruh, C.M, H.V. Larson, T.M. Beetle and A.R. Keene. 1967. The Establishment and Utilization of Film Dosimeter Performance Criteria. BNWL-542, Pacific Northwest National Laboratory, Richland, Washington.

Wilson, R.H. 1987. Historical Review of Personnel Dosimetry Development and Its Use in Radiation Protection Programs at Hanford. PNL-6125, Pacific Northwest National Laboratory, Richland, Washington.

Wilson, R.H., J.J. Fix, W.V. Baumgartner, and L.L. Nichols. 1990. Description and Evaluation of the Hanford Personnel Dosimeter Program From 1944 Through 1989. PNL-7447, Pacific Northwest National Laboratory, Richland, Washington.

Wilson, R.H., and H.V. Larson. 1961. Film Capabilities for High Level Dose Evaluation. HW-71133, General Electric Company, Richland, Washington. 
Appendix A

Derivation of the Asymptotic Relative Efficiency 


\section{Appendix}

\section{Derivation of the Asymptotic Relative Efficiency}

In this appendix, it is shown that for testing the null hypothesis $\beta=0$, the asymptotic relative efficiency (ARE) of the statistic given in Equation (2) is given by the quantity $R=V X / V Z$, with measured doses substituted for true doses, relative to the comparable statistic based on true doses. It is assumed in this derivation that $\mathrm{E}(\mathrm{z} \mid \mathrm{x})=\mathrm{x}$.

Kendall and Stuart (1979) show that the ARE of a procedure based on a test statistic $Y_{2}$ relative to a test based on $Y_{1}$ for testing $\beta=0$ is given by $\left(c_{2} / c_{1}\right)^{2}$, where

$$
c_{k}=E_{k}^{(1)}(0) /\left[\operatorname{Var}\left(\mathrm{Y}_{k}\right) / \beta=0\right]^{1 / 2}
$$

and $E_{k}{ }^{(1)}(0)$ is the first derivative of the expected value of $Y_{k}$ with respect to $\beta$ evaluated at $\beta=0$. For the application here, $Y_{1}$ is the score statistic given in equation 2 , and $Y_{2}$ is the comparable statistic with measured doses $\mathrm{z}$ substituted for the true doses $\mathrm{x}$. Expectations are conditional on the particular times and strata in which cases occurred. The expected values of $Y_{1}$ and $Y_{2}$ are given by

$$
E_{1}(\beta)=\sum_{i} \sum_{j} \frac{1+\beta x_{i j}}{N_{i}\left(1+\beta M X_{i}\right)}\left(x_{i j}-M X_{i}\right)
$$

and

$$
E_{2}(\beta)=\sum_{i} \sum_{j} \frac{1+\beta E\left(x_{i j} \mid z_{i j}\right)}{N_{i}\left(1+\beta M X_{i}\right)}\left(z_{i j}-M Z_{i j}\right)
$$

where $I$ indexes cases, $\mathrm{j}$ indexes observations in risk set $\mathrm{I}, \mathrm{X}_{\mathrm{ij}}$ is the true dose for $\mathrm{jth}$ worker in stratum $I, z_{i j}$ is the measured dose for $j$ th worker in risk set $I, N_{i}$ is the number of observations in risk set $I$, and $\mathrm{MX}_{\mathrm{i}}$ and $\mathrm{MZ}_{\mathrm{i}}$ are the respective means of the true and measured doses in risk set $\mathrm{I}$. The first derivatives of these expressions and their values when $\beta=0$ are as follows:

$$
E_{1}^{(1)}(\beta)=\sum_{i} \sum_{j} \frac{x_{i j}-M X_{i}}{N_{i}\left(1+\beta M X_{i}\right)}\left(x_{i j}-M X_{i}\right) ; E_{1}^{(1)}(0)=V X
$$




$$
\begin{aligned}
& E_{2}^{(1)}(\beta)=\sum_{i} \sum_{k} \frac{E\left(x_{i j} \mid z_{i j}\right)-M X_{i}}{N_{i}\left(1+\beta M X_{i}\right)}\left(z_{i j}-M X_{i}\right) \\
& \text { where } E_{2}^{(1)}(0)=\sum_{i} \operatorname{Cov}_{i}(E(x \mid z), z)=V X
\end{aligned}
$$

The last equality follows because, using basic properties of conditional distributions, it can be shown that $\operatorname{Cov}(E(x \mid z), z)=\operatorname{Cov}(x, z)$, and, with $E(z \mid x)=x, \operatorname{Cov}(x, z)=\operatorname{Var}(x)$.

The expression for $\operatorname{Var}\left(Y_{1}\right)$ given $\beta=0$ is given by $V X$ in equation 3 , and $\operatorname{Var}\left(Y_{2}\right)$ given $\beta$ is given by $\mathrm{VZ}$ Thus, from equation $\mathrm{A} 1, \mathrm{c1}^{2}=\mathrm{VX}, \mathrm{c} 2^{2}=\mathrm{VZ}^{2} / \mathrm{VZ}$ and the $\mathrm{ARE},(\mathrm{c} 2 / \mathrm{c} 1)^{2}$, is given by $\mathrm{R}=\mathrm{VX} / \mathrm{VZ}$ as required.

It is also noted that $\mathrm{R}$ can be written as follows

$$
\begin{aligned}
& R=\frac{\sum_{i} V Z_{i} V x_{i}^{2} /\left(V Z_{i} V X_{i}\right)}{V Z} \\
& =\frac{\sum_{\mathrm{i}} \mathrm{Vz}_{\mathrm{i}} \operatorname{Cov}_{\mathrm{i}}^{2}(\mathrm{x}, \mathrm{z}) /\left(\mathrm{VX} \mathrm{i}_{\mathrm{i}} \mathrm{VZ}_{\mathrm{i}}\right)}{\mathrm{VZ}} \\
& =\frac{\sum_{\mathrm{i}} \mathrm{VZ}_{\mathrm{i}} \mathrm{r}_{\mathrm{i}}^{2}}{\mathrm{VZ}}
\end{aligned}
$$

where $r_{i}$ is the usual correlation coefficient of the true and measured doses in risk set $i$. Thus, $R$ can be interpreted as a weighted mean of the squared correlation coefficients over the risk sets in which cases (or deaths) of interest have occurred. 


\section{- Distribution}

No. of

Copies

\section{QRESITE}

D. Cragle, Director

Center for Epidemiologic Research

Oak Ridge Institute of Science and

Education

P.O. Box 117

Oak Ridge, TN 37831-0117

R. Hornung.

National Institute for Occupational

Safety and Health

4676 Columbia Parkway,

MS R-44

Cincinnati, OH 45226

W. E. Murray

National Institute for Occupational

Safety and Health

4676 Columbia Parkway,

MS \$-44

Cincinnati, $\mathrm{OH} 45226$

\section{FOREIGN}

E. Cardis, Head

Programme on Radiation and Cancer International Agency for Research

On Cancer

150, Cour Albert-Thomas

69372 Lyon Cedex 08

FRANCEE
No. of

Copies

Colin R. Muirhead, Ph.D.

National Radiological Protection Board

Chilton, Didcot

Oxon OX11 ORQ .

UNITED KINGDOM

L. Salmon

8 Upton Close

Abingdon

Oxon OX142A1

UNITED KINGDOM

G. Cowper

4 Cartier Circle

Deep River

Ontario KOJ $1 \mathrm{PO}$

CANADA

\section{ONSITE}

24 Pacific Northwest National Laboratory

J. A. Buchanan

K3-54

J. J. Fix

P7-02

E. S. Gilbert (15)

K3-54 